\title{
Procedimientos fallidos: Disposición al riesgo y legitimación de expectativas normativas en Argentina
}

\author{
Matías Dewey ${ }^{1}$
}

\section{Resumen}

Las elecciones políticas, los procesos judiciales, los actos legislativos y los procesos de decisión administrativos son procedimientos cuya función principal consiste en la legitimación de decisiones vinculantes. Para que estos procedimientos puedan cumplir con su función deben, al igual que otros sistemas, permitir la emergencia de incertidumbre acerca del desenlace del mismo. Éste es un componente estructural indispensable de las instancias procedimentales, en la medida que contribuye a lograr una disposición generalizada, orientada a la aceptación de decisiones con pretensión vinculante. Comenzaremos nuestra exposición poniendo en evidencia que las teorías de la anomia orientadas a explicar el problema de la transgresión de normas en América Latina son una particular lectura del clásico problema de la legitimación racional-legal (I). Dentro de este contexto teórico emprenderemos una caracterización estructural de los procedimientos, de su función y presentaremos la noción de procedimiento fallido (II). La tercera etapa está destinada al fenómeno de la desconfianza y a mostrar datos empíricos que dan cuenta de ella (III). La cuarta parte de la exposición ahondará en las causas de este fenómeno para señalar unos de sus rasgos definitorios: su densidad y arraigo en las expectativas (IV). Concluiremos el presente trabajo haciendo mención a la deflación del derecho como una de las consecuencias más notables de la desconfianza $(V)$.

\section{Failed procedures: risk propensity and legitimation of normative expectations in Argentina}

\section{Abstract}

The political elections, litigation, legislation and decision-making processes are administrative procedures whose primary function is to legitimize decisions binding. If such procedures may carry out its function they need to, like other systems, allow the emergence of uncertainty about the outcome of it. This is an essential structural component of procedures to the extent that contributes to achieve a provision aimed at the widespread acceptance of decisions with binding claim. We begin our exposure showing that the theories of anomie aimed at explaining the problem of transgression of rules in Latin America are a particular way of showing the well known problem of rational-legal legitimacy (I).Within this theoretical context we will make a structural characterization of procedures, their function and we will present the concept of failed procedure (II). The third part is dedicated to the mistrust and to show empirical data that could represent it (III). The fourth part of this work go deep into the cause of this phenomenon showing some of his main defining characteristics: its density and rooted in the expectations (IV). The paper will conclude with reference to the deflation of law as one of the most notable of mistrust (V).

${ }^{1}$ Sociólogo de la Universidad del Salvador (Argentina) y estudiante de doctorado en el Departamento de Ciencia Política de la Universidad de Rostock (Alemania) bajo la dirección del Prof. Dr. Nikolaus Werz (matdewey@uni-rostock.de). El presente trabajo debe valiosos comentarios y sugerencias a Ernesto Garzón Valdés, Claudia Lozano, Cristóbal Rovira Kaltwasser y Nikolaus Werz. 


\section{Introducción}

Una manera de estimar el tiempo disponible en una sociedad es a través de sus normas, en tanto éstas son un modo específico de estructurar el futuro. Esto es especialmente válido para la sociedad moderna que dispone de una señalización del tiempo en gran medida simbólica y que ella misma ha producido (Elias 1988: 7). El sistema de derecho, por ese motivo, está indisolublemente vinculado al porvenir: se ocupa de mostrar un futuro abierto en posibilidades, fijando qué habrá de considerarse como comportamiento no esperado (Luhmann 1987: 129).

El problema a tratar en el presente artículo tiene una estrecha relación con la cuestión de la demarcación del tiempo. En términos generales, el tema que nos ocupa es el de las normas y más específicamente, el de las normas que pertenecen a la estructura del sistema de derecho en el contexto de la sociedad argentina. En este contexto social, una y otra vez este tema aparece como problemática de las ciencias sociales para poner de relieve la incongruencia que existiría entre el texto constitucional y la realidad del mismo.

Este hiato, que desde la ciencia política se lo aborda como el problema de la instauración del Estado de derecho, ha sido observado desde la sociología a través del prisma de dos teorías. La primera, tomando la acepción de Durkheim, se sirve del concepto de anomia para señalar la falta o desintegración de las normas en la mencionada sociedad. En esta línea de análisis se inscribe uno de los precursores de la sociología del continente sudamericano, Gino Germani (Germani 1945), quien se refirió a la anomia a mediados del siglo veinte, y Peter Waldmann (Waldmann 2006) que desarrolló la teoría del Estado anómico. El segundo esquema teórico considera el problema en términos de legitimación y es el utilizado por autores como Carlos Santiago Nino quien, al describir el caso argentino, aunque se valga de un término como el de "anomia boba" (Nino 1992), se inclina claramente hacia una interpretación en términos de legalidad o ilegalidad. Un segundo autor que puede ser clasificado dentro esta segunda opción teórica es Guillermo O’Donnell. Mediante conceptos como accountability horizontal y vertical este autor pretende dar cuenta, más minuciosamente, de las dificultades que encuentran las democracias para lograr el imperio de la ley (O’Donnell y Méndez 2002, O’Donnell 2007).

Realizando un ejercicio de abstracción puede afirmarse que desde una perspectiva sociológica estos han sido los dos accesos a la problemática de las constituciones y la realidad de las mismas ${ }^{2}$. A través de ellos se ha intentado dar una respuesta a la disparidad entre expectativas normativas que se anclan en el sistema de derecho y aquellas del mismo tipo que forman parte de otros sistemas normativos paralelos.

\footnotetext{
${ }^{2}$ Estos dos caminos no niegan la posibilidad de influencias mutuas. En efecto, no es posible desconocer la influencia de Max Weber en el esquema teórico de Gino Germani - por ejemplo, con la distinción entre acción prescriptiva, electiva y anómica -, así como tampoco la de Durkheim en ciertos aspectos de la obra de Carlos S. Nino.
} 
Desde la concepción de la constitución normativa de la sociedad, el enfoque de la anomia afirma la posibilidad de que las normas se debiliten o falten ${ }^{3}$. En este contexto teórico, no es extraño entonces que tanto a Germani como a Waldmann se les haya presentado la necesidad de señalar cuáles son las fuentes de la solidaridad que ellos ven decrecer. De forma diversa, ambos han sido coherentes con las idea de Durkheim puesto que, ante la imposibilidad de recurrir a una conciencia colectiva propia de las sociedades tradicionales, admitirán que el Estado y las organizaciones intermedias son fuente de normatividad en la sociedad moderna (Durkheim 1994, Lukes 1973: 268, Girolda 2005: 29). La consecuencia de este proceso, que deriva en la consideración de la instancia estatal, es un acercamiento ineludible a la teoría de la dominación racional de Max Weber y un simultáneo cambio de perspectiva que consiste en amalgamar la teoría de la anomia junto a la teoría de la dominación racional. Un ejemplo que confirma nuestra afirmación es la siguiente definición:

"Proponemos decir que una situación social es anómica cuando faltan normas o reglas claras, consistentes, sancionables y aceptadas hasta cierto punto por la sociedad para dirigir el comportamiento social y proporcionarle una orientación" (Waldmann 2006: 13)

Como podrá advertirse, la definición que aquí se ensaya guarda escasa relación con las usuales conceptualizaciones de la anomia - ya sea en la versión de Durkheim o de Merton - y, por el contrario, presenta una evidente afinidad con la pregunta por las posibilidades de que exista una creencia que legitime la dominación racional. Resulta claro que el problema subyacente, si se plantea en términos de Weber, es cómo el Estado "intenta despertar y cuidar la creencia en la legitimidad" del mismo (Weber 1997). Por ese motivo, la referencia a normas "sancionables" y "aceptadas socialmente" remite directamente a la cuestión de la creencia en la legitimidad de un orden normativo y a la capacidad de éste para aplicar las disposiciones.

La argumentación anterior, está destinada a mostrar cómo ciertas reflexiones que describen el caso argentino en términos de anomia contienen en realidad una clara referencia al problema de la legitimación, en tanto aluden a la posibilidad de que las decisiones vinculantes adoptadas por el sistema político logren ser aceptadas. Esto nos lleva a plantear un problema al que Max Weber no dio solución y al que Niklas Luhmann responde con su teoría de la legitimación por procedimientos (Luhmann $1983)^{4}$

${ }^{3}$ Partiendo de la clásica distinción entre sociedad tradicional y moderna, que funge en el pensamiento de Germani como eje interpretativo a partir del cual buscará explicar procesos de desajuste estructural y psicosocial, la anomia señala un Estado de transición en donde las normas se encuentran debilitadas; una situación en la cual los lazos sociales no encuentran correspondencia con una realidad que se encuentra en cambio (Germani 1945, 1971). Por otro lado, en Waldmann se advierte que las normas que el Estado tiene por obligación hacer cumplir, se debilitan y desaparecen como norma de comportamiento a seguir a causa de un Estado que no logra el disciplinamiento de sus cuadros administrativos (Waldmann 2006).

${ }^{4}$ Esta crítica indica que aún cuando Weber afirma la necesidad de una creencia en la legalidad de un orden establecido, deja sin solución el problema de cómo la misma puede emerger. Esta cuestión no se menciona en Wirtschaft und Gesellschaft (Economía y Sociedad) pero tampoco en su Rechtssoziologie (Sociología del derecho). En esta última, tal 
En efecto, una vez admitidas tanto las dificultades teóricas que exhibe el concepto de anomia, así como la necesidad de visualizar el problema en términos de aceptación de las normas, entonces es preciso investigar cuáles son los mecanismos que posibilitan o dificultan la emergencia - o no - de la creencia en la legitimidad de las normas emanadas del sistema político. Dirigir la observación en esta dirección sin duda constituye un avance en el conocimiento, sobre todo en vistas de que aquellos análisis que efectivamente consideran la perspectiva de la "legitimación/no legitimación" para analizar el problema de las normas, no van más allá de una descripción que no profundiza en las causas ni es capaz de derivar teóricamente las consecuencias ${ }^{5}$.

En virtud de lo mencionado hasta el momento, el análisis que emprenderemos tomará como referencia la teoría de la legitimación por procedimientos de Niklas Luhmann. Sin embargo, nuestro interrogante ya no será "cómo tal creencia [en la legalidad] puede tener lugar" (Luhmann 1983: 29), sino el contrario; esto es: ¿porqué la mencionada creencia en la legalidad no puede emerger? A los efectos de dar una respuesta a este interrogante dividiremos nuestra argumentación en cuatro partes. En primer lugar nos referiremos a la teoría de la legitimación por procedimientos y presentaremos el concepto de procedimiento fallido. A continuación se le dará sustento empírico a nuestra propuesta teórica mostrando los resultados de los denominados estudios sobre victimización. La tercera y cuarta parte del trabajo están destinadas a indagar las causas y las consecuencias de los procedimientos fallidos.

\section{Procedimientos: función y déficit estructural}

La teoría de la legitimación por procedimientos es una respuesta a la pregunta por las posibilidades de emergencia de la creencia en la legitimidad de decisiones vinculantes emanadas del sistema político; es una explicación acerca del modo en que puede llevarse a cabo una institucionalización de expectativas normativas específicas. En otras palabras, Luhmann se pregunta por la legitimidad de la legalidad y propone al procedimiento como llave explicativa. En su ya clásica obra, Legitimation durch

\footnotetext{
como señala Luhmann, no se analizan los procedimientos de producción ni de aplicación del derecho como mecanismos generadores de legitimidad.Véase: Weber 1997: 124, 387 ss.

${ }^{5}$ Este es el caso de conceptos como "accountability” de Guillermo O’Donnell que define, por citar un ejemplo, a este término en su versión "horizontal" como "la existencia de instituciones estatales que tienen el derecho y el poder legal de, y están fácticamente dispuestas y capacitadas para, emprender acciones que van desde un contralor rutinario hasta sanciones legales o el impeachment, en relación con actuaciones u omisiones de otras instituciones del Estado que pueden, en principio o presuntamente, ser calificadas como ilícitas" (O’Donnell 2007: 99). Esta formulación alude al mismo problema que intenta destacar Waldmann cuando se refiere a la incapacidad de los Estados en América Latina para controlar los procesos que tienen lugar en su interior. El aparato estatal de los países de la región "nunca ha conseguido refrenar ni disciplinar a sus propios miembros y órganos" (Waldmann 2006: 18). Aun cuando mediante estas propuestas se pueda argumentar que un suceso de corrupción Y tuvo lugar porque falló el control estatal Z, queda sin respuesta porqué falla $\mathrm{Z}$ y lo más importante: porque siempre falla $Z$. Es decir, se señala la brecha entre las leyes y su realidad, se manifiesta qué debería funcionar para reducir la misma, pero no se ahonda en las razones que conducen a la transgresión de normas o, en definitiva, no se explica porqué no surge una creencia en el entramado normativo estatal.
} 
Verfahren (Legitimación por procedimientos), define a la legitimación del siguiente modo:

"[...] disposición generalizada para aceptar decisiones con un contenido todavía indeterminado dentro de ciertos límites de tolerancia” (Luhmann 1983: 28).

Si se quiere traducir la problemática planteada por Luhmann en términos de Weber, entonces nos hallamos ante la cuestión de la creencia en la legitimidad de la dominación legal.Y es precisamente en este punto donde viene a ser esclarecedor su planteo de la legitimación por procedimientos. En efecto, el problema no resuelto por Weber es el del paso de la legitimidad a la legalidad (Luhmann 1983, Heidorn 1982) puesto que no se brinda una explicación sobre los procesos que logran sumisión por parte de un colectivo a un conjunto de disposiciones abstractas, distantes e impersonales. En el caso de la dominación legal, Weber no proporciona una explicación acabada de qué habría de producir la adhesión a un conjunto de normas racionales y, sobre todo, cuando la amenaza constante de violencia física, tal como afirma Luhmann, es un «bien escaso» (Luhmann 1983: 28) que de ningún modo puede fundar un orden duradero por sí mismo. Esto sugiere que un mínimo de adhesión debe existir y que la pregunta decisiva es el modo en que la misma ha de tener lugar.

La crítica de Luhmann a Weber se inserta en este contexto y observa que los procedimientos son sistemas sociales cuya función es la constitución y transformación de expectativas; sistemas sociales que, mediante una estructura de roles y una reglamentación jurídica, son capaces de crear un clima social y provocar la emergencia de una disposición orientada a la aceptación de las decisiones que se toman en los procedimientos. Los diferentes actores que intervienen, por ejemplo, en la producción de las elecciones políticas - electores, candidatos, medios de comunicación, propaganda o partidos políticos - recrean dicho clima social y la contribución de cada parte lleva a la introducción de temas nuevos -mediante encuestas, noticias, escándalos, pronunciamientos, etc. - que mantienen la atención de todos y se orientan a esperar un resultado. Todo promete que habrá un desenlace que traerá ganadores y perdedores; los primeros aceptarán sin problemas el resultado y los segundos, aunque no lo acepten, deberán hacerlo porque nos les queda margen para la protesta so pena de profundizar el propio descrédito 6 .

En primer lugar, debe tenerse en cuenta que Luhmann desarrolla su teoría de la legitimación a partir de una particular concepción de la sociedad moderna, donde la idea de complejidad desempeña un papel de primera importancia. Complejidad de la sociedad significa un aumento constante de los temas y de las posibilidades disponibles dentro del mismo sistema social, al tiempo que para el sistema político representa un desafio con el cual debe confrontar. La sociedad moderna, sin referen-

${ }^{6}$ Esto es sin duda problemático cuando aparece la observación de fraudes, corrupción o se trata de gobiernos autoritarios. En estos casos, la protesta es el correlato de la no aceptación de las decisiones vinculantes y manifestación directa de la desconfianza en el derecho. 
cias unívocas y diferenciada según ámbitos de comunicación específicos, es para el sistema político una fuente constante de demandas que requieren respuestas rápidas y frecuentemente contradictorias (piénsese en leyes impositivas o referidas a la educación, que están en continua discusión y cambio). El sistema político debe ser capaz de lidiar con ese constante cambio de temas y problemas que varían, y conforme a ello tomar decisiones que gocen de legitimidad. Esta tarea, argumenta Luhmann, no puede lograrse sobre la base de un consenso ideológico o un convencimiento general en torno a valores; por el contrario:

"Por eso [el reconocimiento de decisiones] depende en menor medida de encendidos convencimientos y mucho más de una aceptación libre de motivos e independiente de las particularidades de personalidades individuales. Esta aceptación es previsible sin que sea requerida demasiada información concreta" (Luhmann 1983: $32)$.

Esta postura, criticada sobre todo por aquellos que ven la necesidad de fundar la legitimación de un orden en determinados entramados discursivos y racionales (Habermas 1973, 1976: 274 ss.), es la consecuencia de los requerimientos de una sociedad que no puede afrontar tales desafios partiendo de un consenso anclado en valores o en ideologías invariables; el carácter estático de tales convencimientos llevarían a dejar sin capacidad de reacción al sistema político (Luhmann 1983: 251). Es más, éste, en aras de cumplir con la función de asegurar una aceptación de las decisiones vinculantes que él mismo toma, debe desprenderse y buscar independencia de tales convencimientos universales. Debe diferenciarse de los convencimientos que propone la religión o de férreos convencimientos en materia económica; debe conservar flexibilidad para adaptarse a demandas continuas y variadas que provienen de distintos sectores y reclaman respuesta. Entonces ya no son verdades trascendentales o consensos sobre valores los que fundan un proceso de legitimación, sino las decisiones que se van tomando conforme al marco regulativo del derecho positivo.

Esta tesis procedimental de la legitimación identifica cuatro mecanismos que crean un "clima social" (Luhmann 1983: 34) propicio para el reconocimiento de las decisiones vinculantes: los procedimientos judiciales, las elecciones políticas, los procesos administrativos y los legislativos. Todos ellos son considerados por Luhmann como sistemas sociales que posibilitan y promueven el aprendizaje y la aceptación de las normas. Es de vital importancia para la comprensión del fenómeno descrito que se tenga en cuenta el carácter emergente de los sistemas sociales denominados procedimientos. El modelo de la emergencia, en contraposición al clásico modelo de división del todo en partes, pretende señalar la aparición de una nueva constelación - que Luhmann llega a señalar como clima social - que facilita la aceptación de las normas. Pero aun más: se trata de instancias que coadyuvan a una reestructuración de las expectativas normativas, función principal del procedimiento. Entonces, éste 
constituye un momento de aprendizaje de la nueva situación o, en otras palabras, de la posible aceptación de las decisiones.

La emergencia de estos sistemas sociales específicos o instancias procedimentales, vale aclarar, tiene lugar en el marco de reglamentaciones jurídicas aunque no puede ser reducida a éstas últimas. La legitimación por procedimientos no está referida a la justeza de las decisiones adoptadas - en el sentido de una búsqueda de la verdad - en virtud de que ello no explica la forma en que se llega a una aceptación de las decisiones. La legitimación por procedimientos asume que la situación está regulada jurídicamente, pero también que en la participación en los mismos opera un cambio en el nivel de lo esperable y que el programa jurídico es uno de los componentes estructurales que posibilitan la emergencia de dicha reestructuración. En palabras de Luhmann:

[...] se trata mucho más de una reestructuración de lo esperable a través de un proceso de comunicación fáctico que transcurre conforme a reglamentaciones jurídicas; es decir, se trata de un suceso real y no de una relación de sentido normativa (Luhmann 1983: 37).

Ahora bien, ¿cuál es el significado que tiene esta propuesta teórica para nuestra pretensión de explicar el hecho de que en Argentina se advierten déficits en la "creencia" social en las normas del sistema de derecho? Partiendo de los procedimientos que producen estructuras normativas, la respuesta rezaría: en los mismos existen falencias estructurales que impiden el logro de su función. Esta afirmación se desprende de datos empíricos según los cuales en la Argentina imperan altos niveles de desconfianza hacia los representantes de roles ligados a los procedimientos ${ }^{7}$. Esta desconfianza generalizada, que puede ser entendida como la falta de una confianza sistémica, tendría su origen en un déficit propio del sistema de derecho.

Como veremos más adelante, la naturaleza de dicho déficit no es antojadiza, sino que responde a una historia de no cumplimiento de su función. Si el derecho no reacciona cuando sus normas han sido violadas, entonces se pone en duda su capacidad para ser un medio válido de protección la próxima vez; esto es, deviene en un objeto de desconfianza. En este contexto, los procedimientos pierden un componente preciado a la hora de procurar una aceptación de las decisiones: la incertidumbre acerca del desenlace del procedimiento; es decir, el no saber cómo será el desenlace del mismo (Luhmann 1983: 40 ss, Elster 2007, Smithson 1989, Burden 2003).

Esta incertidumbre sobre el desenlace, que debe interpretarse también como confianza en un procedimiento sobre el cual no se conoce su desarrollo pero se participa con la esperanza de tener éxito, no es posible en circunstancias en las que impera la desconfianza en los jueces, en los policías y en los distintos representantes del Estado. El correlato de la desconfianza es una certeza que hace de dicha desconfianza algo ${ }^{7}$ Los datos que fundamentan esta afirmación se presentan en el apartado III. 
tolerable; el no confiar debe transformarse en una certeza en la cual se confia afirmándola. Se sostiene que los jueces y los políticos son todos corruptos y se afirma ello luego de haberse depositado confianza. Por lo tanto, en el presente trabajo se afirma que dichas certezas minan cualquier posibilidad de aceptación de las decisiones adoptadas en los procedimientos y que ello se genera por la falta de incertidumbre presente en el transcurso del procedimiento.

Esto nos lleva a proponer el concepto de procedimiento fallido ${ }^{8}$. Con él se quiere expresar que la función del mismo se encuentra bloqueada; se sostiene que existen defectos estructurales que impiden una reorientación de las expectativas y para ello nos apoyamos - como se verá en la próxima sección - en una serie de datos empíricos que ponen de relieve la presencia de la desconfianza en la comunicación cotidiana y la pérdida de confianza en sistemas como el derecho. El déficit en la confianza sistémica significa una permanente interrupción del proceso que se lleva a cabo en los procedimientos dado que continuamente se pone en tela de juicio la función de importantes roles. En otras palabras, la función de los procedimientos se ve bloqueada porque que la desconfianza interfiere en su capacidad para generar disposición orientada a la aceptación de normas. En este contexto, es importante mencionar que la incertidumbre es un componente estructural central que permite que exista disposición para aceptar decisiones vinculantes. Luhmann afirma que:

"La incertidumbre es esencial para los procedimientos. Ella otorga a los participantes el incentivo para contribuir al procedimiento con nuevas decisiones. La incertidumbre es la verdadera fuerza del procedimiento; aquel factor verdaderamente legitimante" (Luhmann 1983: 51).

La incertidumbre acerca del resultado del procedimiento funge como el motor del mismo porque ella impele a las partes a impulsar sus propios intereses. Teniendo como precondición a la incertidumbre, los participantes se esfuerzan hacia la obtención de determinados fines, es decir, ellos permanecen en el procedimiento tomando parte en él. Por otra parte, la incertidumbre posibilita la asunción de roles y la cuidada representación de los jueces - en el caso de los procedimientos jurídicos - en tanto terceros neutros.

Llegado el caso de que incertidumbre apenas tenga presencia en los procedimientos, entonces tampoco es posible una aceptación de las decisiones o, en otros términos, no se aprende de la nueva situación. Como muestran ciertos indicadores de los niveles de confianza, éste sería el caso de la Argentina, donde la incertidumbre sobre

\footnotetext{
${ }^{8}$ Frente a una posible asociación con el concepto de "failed state" conviene aclarar que el procedimiento fallido no supone la falta de la estructura estatal aunque tampoco la disolución de la misma o la falta de control sobre el territorio. Nuestro concepto se aleja de los "failed states" en la medida que los procedimientos pueden fallar sin que ello signifique la posibilidad de afirmar que el Estado ha perdido el monopolio de la fuerza. Si de un modo ideal se aceptase que los Estados fallidos se encuentran en un extremo de una línea continua y en otro los Estados "perfectos", nuestro concepto adoptaría una posición intermedia. La observación sobre los procedimientos se refiere al funcionamiento interno de la democracia.
} 
el resultado del procedimiento es prácticamente inexistente. Muy por el contrario, allí no es posible encontrar incertidumbre, sino su opuesto: la certidumbre. Ésta, sin embargo, que surge como correlato de la desconfianza, posee una connotación negativa. Se trata de una certidumbre en el sentido de un profundo convencimiento de que no es posible confiar en las decisiones tomadas por representantes de roles. Esta certidumbre, por ejemplo, se manifiesta en afirmaciones categóricas tales como que los políticos, los jueces o los policías serían corruptos.Y valga la aclaración: esta certidumbre es destructiva para los procedimientos. Ella es la causa de su carácter fallido.

Debe quedar claro que, en este contexto, la incertidumbre descrita por Luhmann también significa confianza. Quien dispone de confianza en ciertos roles como el de un juez o de policía, permanece envuelto en el procedimiento aunque no se sepa si se ganará o se perderá al final del mismo. Expresado de otro modo, puede decirse que la confianza, a pesar de la incertidumbre, genera disposición al riesgo. Mientras tanto, un fenómeno opuesto se deriva de la certeza: se cree saber anticipadamente que tanto jueces como políticos y policías no son dignos de merecer confianza. La desconfianza brinda la posibilidad de generar certeza respecto a lo inapropiado del confiar.

Haciendo referencia a casos históricos concretos, Jon Elster analiza diversos procedimientos de justicia transicional bajo el supuesto de que la incertidumbre es una precondición estructural para el éxito del mismo (Elster 2007: 109 s). Según este autor, un indicador de la falta de incertidumbre en los procedimientos es cuando un observador puede predecir con seguridad el resultado al cual se arribará. Por ejemplo, una dictadura es una muestra acabada de falta de incertidumbre (Przeworski 1988: 62). En casos como estos, los procedimientos se prestan a ser interpretados como rituales (Luhmann 1983: 40 s).

Esta ritualización de los procedimientos viene a señalar que su poder de transformación de las expectativas a través de la incertidumbre fue sustraído; significa que el déficit en incertidumbre tiene un efecto destructivo para los procedimientos ya que su función, consistente en producir expectativas que acepten la nueva situación, se encuentra coartada. En este sentido, estas estructuras defectuosas pueden ser denominadas "procedimientos fallidos".

Es necesario, al mismo tiempo, dejar en claro que la observación de estas estructuras no afirma la incapacidad o inutilidad de los procedimientos. Tanto los procesos jurídicos, las elecciones políticas, los procesos de decisión administrativos como lo procesos legislativos son instancias que funcionan sólo a través del derecho y se estructuran mediante programas condicionales ${ }^{9}$. Dichos programas condensan expectativas

\footnotetext{
"Un programa es un complejo de condiciones de corrección [...] del comportamiento" (Luhmann 1984) y se diferencia de otros contextos de expectativas como las "personas", los "roles" y los "valores". Mientras que el código regula la producción de diferencias - justo/ injusto; poder/ no poder; trascendente/ inmanente, etc. -, el programa establece los criterios para asignar los valores del código. Los programas condicionales - leyes, procedimientos - determinan las
} 
normativas que no pueden ser fácilmente abandonadas y, por consiguiente, pese a todo su déficit, siguen siendo aplicados. En realidad, este proceso no pone en duda la estructura del derecho, sino que pone de relieve la emergencia de estructuras paralelas que fungen como equivalentes funcionales del derecho y absorben la inseguridad generada por el derecho. Si éste no puede ser tomado como un camino válido para la canalización de expectativas normativas y los procedimientos no cumplen con su función, entonces la confianza se reorienta y encuentra un espacio propicio en contextos de expectativas que efectivamente tengan la capacidad de estabilizar contrafácticamente lo que se espera. De este modo, el fenómeno que queda en evidencia cuando los procedimientos fallan, es la formación de contextos de expectativas normativas paralelas que disponen de altos niveles de confianza.

\section{La desconfianza en los estudios sobre victimización}

Los estudios sobre victimización consisten en encuestas que, entre otros objetivos, pretenden arrojar luz sobre tres aspectos. En primer lugar, establecer qué porcentaje de la población denuncia los delitos; segundo, qué tipos de delitos son los más extendidos y por último, las razones por las cuales efectivamente se recurre a las autoridades y las razones por las cuales no. La relevancia de estos estudios en el presente trabajo reside en que gracias a ellos se pueden tener indicios acerca de la confianza en aquellos órganos del sistema de derecho que se ocupan del tratamiento del delito o, en términos más abstractos, de estabilizar las expectativas normativas. Asimismo, al tratarse de encuestas promovidas por las Naciones Unidas, se dispone de cuestionarios altamente estandarizados que permiten la comparación internacional. En la Argentina estos estudios comienzan en el año 1995 en la Ciudad de Buenos Aires y en 1996 en la Provincia de Buenos Aires, ambos efectuados con carácter experimental. A partir del año 1997 se expanden a otros centros urbanos de importancia como Rosario, Córdoba y Mendoza, y comienza la serie de mediciones que de forma ininterrumpida llegan hasta la actualidad, tomando como modelo básico el propuesto por el United Nations Interregional Crime and Justice Research Institute (UNICRI).

Según los resultados de esta encuesta durante el período 1997/2003 en el Gran Buenos Aires el $42 \%$ de la población sufrió algún tipo de delito ${ }^{10}$. Comparativacondiciones necesarias para que el lado positivo del código - conforme al derecho - pueda ser asignado. Los programas con arreglo a fines controlan las condiciones mediante las cuales es posib le alcanzar un fin. Ejemplo para este último caso son los programas de la ciencia - teorías y métodos - a través de los cuales se fija las condiciones para poder afirmar una verdad. Mediante los programas condicionales se asigna retroactivamente los valores expresados en el código. ${ }^{10}$ La encuesta es aplicada por la Dirección Nacional de Política Criminal (DNPC) en los centros urbanos de Ciudad de Buenos Aires, Gran Buenos Aires, Ciudad de Rosario, Ciudad de Córdoba y Gran Mendoza. Las definiciones dadas por organismo son: "Población victimizada general": Entrevistados que declaran haber resultado victimizados de al menos un delito (entre los delitos medidos: robo o hurto de vehículo automotor, robo o hurto de objeto en vehículo, vandalismo sobre vehículo automotor, robo o hurto de moto o ciclomotor, robo o hurto en vivienda, tentativa de robo 
mente esto significa aproximadamente el doble delitos que Suiza con 18\%; Canadá con 24\%; Finlandia y Cataluña (España) con 19\%; Dinamarca, Escocia y Polonia con 23\%; Inglaterra con 26\%; Holanda y Suecia con 25\%; Francia, Estados Unidos y Bélgica con 21\%. El promedio de todos estos países arriba al $21 \%$ (Van Kesteren 2000). Datos interesantes surgen cuándo se pregunta por la cantidad de individuos que denuncian los delitos ante las autoridades del sistema judicial. El promedio de personas que recurrieron a la policía o a los jueces en esta región del país durante el período antes mencionado es de 25, $4 \%$; es decir, casi el $75 \%$ de los afectados no hace la denuncia los delitos (Gráfico 1).

Gráfico 1. Cantidad de denuncias de delitos en el sistema penal. Gran Buenos Aires, año 2003.

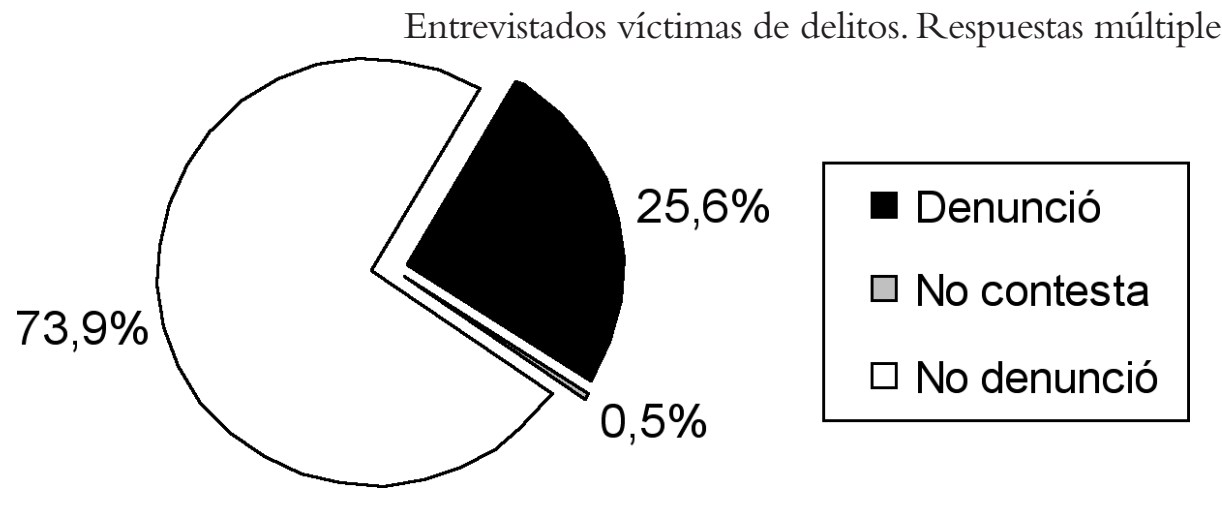

Aunque deba consignarse que en ningún país se denuncian el cien por ciento de los casos, sin embargo las diferencias son muy llamativas. En países como Dinamarca el $60 \%$ de los delitos son denunciados a la policía. Le siguen Suecia y Irlanda del Norte con 59\%, Holanda con 58\%, Bélgica con 56\%, Inglaterra con 55\%, Suiza con 53\%, Francia y Escocia con 52\%, Estados Unidos con 50\%, Australia con 49\%, Canadá con 47\%, Finlandia con 46\%, Polonia con 38\%, Cataluña (España) con 37\%, Japón con $37 \%$ y Portugal con 32\%. El promedio arroja la cifra de $50 \%$ de denuncias del total de personas victimizadas en el año 2000 (Van Kesteren 2000); es decir, el doble del caso argentino. Como dato adicional vale la pena mencionar las razones argüidas por los entrevistados para los casos de no denuncia. En el Gran Buenos Aires el 44\%

o hurto en vivienda, robo con violencia contra las personas, hurtos personales, ofensas sexuales, lesiones o amenazas, corrupción y otros delitos) en el período determinado. "Denuncia general": Porcentaje de las victimizaciones detectadas por la encuesta en el conjunto de los hechos delictuosos medidos que indican haber hecho la denuncia, respecto del total de las victimizaciones. "Denuncia de hechos robos y hurtos": Porcentaje de las victimizaciones detectadas por la encuesta en el conjunto de los hechos delictuosos medidos que indican haber efectuado la denuncia, respecto del total de victimizaciones contra la propiedad. Al igual que en la denuncia general, se considera a los fines del presente estudio como hecho denunciado exclusivamente a aquellos hechos respecto de los cuales el entrevistado indica que fue realizada una denuncia al sistema penal, es decir, a la policía o a la fiscalía o a un organismo judicial. Los datos sobre la Argentina aquí expuestos están disponibles en: $\underline{\text { http://wwwpolcrim.jus.gov.ar }}$ 
de las personas victimizadas que no realizó la denuncia del delito declaran que no lo hicieron porque "la policía no habría hecho nada". Esta desconfianza hacia la institución policial se encuentra reforzada por casi un 4\% de entrevistados que admiten no haber realizado la denuncia porque "la policía la desalentó" o a causa de "miedo o desconfianza" hacia la misma. Estas cifras vienen a significar que cerca del $50 \%$ de los no denunciantes desconfia de la policía como instancia válida a la cual acudir en caso de ser víctima de un delito (Gráfico 2).

Gráfico 2. Motivo de no denuncia del delito. Gran Buenos Aires, año 2003.

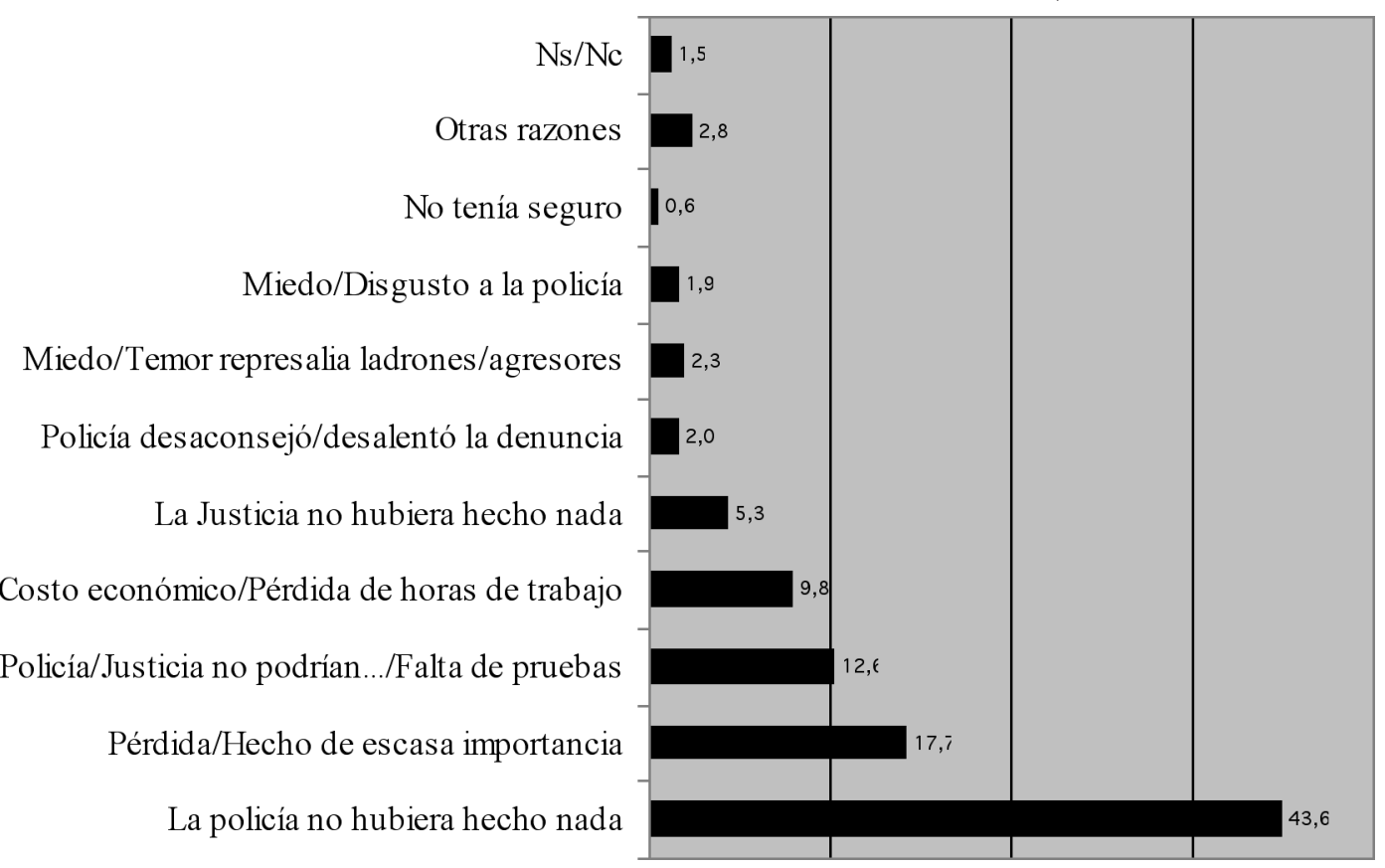

Base:Víctimas de delitos que no denunciaron. Respuestas múltiples.

Que un 75\% de las personas victimizadas entre los años 1997 y 2003 no haya hecho la denuncia en ninguna instancia del sistema penal y que de ese porcentaje más del $43 \%$ declare que "la policía no habría hecho nada", viene ser una prueba palpable de la desconfianza institucionalizada, relacionada en este caso, a la policía. Una comparación entre países latinoamericanos muestra que, aunque la Argentina ocupa un lugar destacado en cuando a los niveles de denuncia de delitos, existe una brecha de considerable amplitud con otros países.

Antes de continuar con la cuarta parte de la exposición es necesario puntualizar que estos índices de desconfianza también aparecen en estudios tales como los del Latinobarómetro, en el Índice de Confianza en la Justicia de la Universidad Torcuato Di 
Tella ${ }^{11}$ y en investigaciones cualitativas sobre la confianza en las instituciones (Sautu 2004).

\section{Orígenes de la desconfianza y diferenciación del derecho}

La desconfianza a la cual aquí se hace referencia no debe ser pensada como un simple agregado de datos de encuestas y tampoco como un estado de ánimo desfavorable o un clima social adverso a la credibilidad de ciertos roles. La sustracción de elevados niveles de incertidumbre cuyo valor estructural es de primera importancia para los procedimientos, sólo es comprensible si se admite el vigor de esta desconfianza y la potencia de las certezas que de ella se desprenden. Contrariamente a la idea de que este fenómeno de la desconfianza es pasajero o modificable mediante intervenciones orientadas a "mejorar la imagen" de representantes de roles, aquí sostenemos que la desconfianza es en sí misma una estructura de expectativas y que, en algunos casos, llega a ser una semántica ${ }^{12}$ cuya elemento principal es la certeza de que si se confía, una decepción sobrevendrá.

Expresado en términos sencillos, esta desconfianza es el resultado de un aprendizaje a partir de continuas frustraciones. Se tenían ciertos derechos y ellos fueron violentamente sustraídos, sin que sean reemplazados o devueltos. Se tenían bienes en el banco y éstos nunca fueron devueltos. Se sufrió un robo y la policía no reaccionó o su participación agravó la situación. Es decir, pensar en una estructura de la desconfianza significa, en términos de la teoría de sistemas, que ciertas expectativas normativas no fueron reestabilizadas o que no recibieron un adecuado tratamiento por parte del sistema de derecho. Esta estructura de la desconfianza impregna la comunicación cotidiana y aparece bajo diferentes formas - chistes, modos de proceder, refranes, etc. - que actualizan la estructura de la desconfianza.

Una de las principales consecuencias de las expectativas de la decepción es que dentro del sistema se van estructurando modos de reacción ante ella que finalmente producen la formación de estructuras, ya no de la desconfianza, sino de la confianza.

\footnotetext{
${ }^{11}$ Según el Informe 2005 del Latinobarómetro, los entrevistados creen que en Argentina el 74\% de los políticos son corruptos.Véase: <www.latinobarometro.org>. Por otra parte, el Índice de Confianza en la Justicia es elaborado por la Universidad Torcuato Di Tella de Argentina y resulta ser una síntesis de dos subíndices, uno perceptual y otro conductual. Uno de los datos significativos que se desprenden de esta encuesta elaborada desde el año 2005 es la discordancia entre el índice conductual y el de percepción de la justicia. En efecto, mientras que los encuestados afirman que llegado el caso - recibir un cheque sin fondos, divorciarse del cónyuge o ser despedido del trabajo - recurrirían a la justicia, cuando se les pregunta acerca de los principales atributos de la justicia - imparcialidad, honradez y eficiencia - predominan las opiniones negativas. Los datos que suministra el ICJ presentan un fuerte nivel de crítica dirigido hacia la justicia argentina.

${ }^{12}$ Algunas investigaciones que destacan el fenómeno de la desconfianza permiten argumentar a favor de una semántica de la misma. Aunque este es un campo inexplorado por la sociología hay desarrollos provenientes de la historia y la literatura que abonan esta línea de investigación (véase: Saguier 1992, Morales Saravia 2001). Esta semántica sería un emergente de una historia de expectativas lesionadas no reestabilizadas. Por semántica aquí se entiende a un conjunto de reglas de procesamiento del sentido y a una situación donde este último logra un gran nivel de generalización y relativa independencia de situaciones concretas (Luhmann 1980: 19). La frustración, según esta hipótesis, habría sido incorporada a la estructura de expectativas de modo de convertirse en algo esperable.
} 
Si las expectativas dicen que del policía, del juez y del político se debe desconfiar, pues éstos son roles que no pueden asegurar las expectativas normativas y se tiene como consecuencia la paralela formación de estructuras de expectativas sobre roles que sí tienen la capacidad de asegurar lo que se espera ${ }^{13}$.

Las implicaciones de estas observaciones son vastas y requieren que se responda a una serie de interrogantes que inmediatamente pueden formularse. Una estructura de la desconfianza referida a roles que estructuran el sistema político y de derecho y, consecuentemente, una comunicación sobre normas que no opera haciendo referencia a la distinción "conforme al derecho/no conforme al derecho", implica no sólo un proceso de aprendizaje de la decepción, sino una historia de permanentes situaciones en las que el sistema de derecho no reaccionó, ya sea por cuestiones internas o, como afirma Marcelo Neves, porque el sistema fue asimetrizado externamente (Neves 1992: 81 ss.). Con esto se quiere decir que la estructura de la desconfianza aludida anteriormente es el producto de la historia misma del sistema de derecho o de la historia de su debilidad para reestabilizar las expectativas normativas.

El sistema de derecho en su actual forma es una máquina histórica que se encuentra condicionada por su propio pasado. La tesis que aquí se defiende, por lo tanto, señala que tales condicionamientos consisten en frustraciones de expectativas no estabilizadas. Por este motivo, la comunicación sobre normas no puede evitar que su propia historia de frustraciones sea tematizada continuamente.

Si bien el estado actual del sistema es el resultado de toda su historia, ésta entendida como el producto de todos los sucesos que tuvieron lugar en él, es posible aislar determinados sucesos de indudable significancia y cuya tracción ha sido suficiente para direccionar la comunicación dentro del sistema. Los sucesos históricos a considerar pueden ser variados y con ellos no se pretende realizar una historia del sistema de derecho en Argentina.

La referencia a sucesos históricos remite, sobre todo, a un problema en el que confluyen una preocupación ya clásica dentro de las ciencias sociales y los nuevos desarrollos sobre el proceso de diferenciación funcional. Por un lado, cabe mencionar la reflexión clásica sobre la formación del Estado en América Latina y, por otro, la atención puesta en las posibles formas de diferenciación en el mismo continente, tal como lo hace Aldo Mascareño en relación a la periódica intervención del sistema político sobre otros sistemas funcionales (Mascareño 2001, 2004). Afirmar que el decurso actual de la comunicación está orientado por sucesos pasados, en última instancia conduce a una consideración de la historia del sistema y, con ello, se desemboca en la cuestión de la diferenciación del sistema de derecho.

\footnotetext{
${ }^{13}$ Uno de ellos, tal como lo revelan los trabajos etnográficos de Javier Auyero en el Gran Buenos Aires, es el de "mediador". Su rol funge como punto de enlace de expectativas que, junto a otros mediadores, demarcan un campo "gris" entre lo público y lo privado, entre el Estado y el público (Comp. Auyero 2001, 2007).
} 
Si se sostiene junto con Luhmann que la diferenciación, en este caso funcional, se sustenta en un diferenciación de roles (Luhmann 2005c: 125), entonces se tienen elementos para observar un caso concreto como el de Argentina. Allí, la implantación del sistema judicial permite ver un proceso que consistió en la introducción de una legislación que debió ser custodiada por roles - policías, jueces, empleados estatales varios - que se incrustaron en un contexto de expectativas ajenas a los mismos. Los nuevos códigos y reglamentaciones que pretendían regular la vida cotidiana alteraron una comunicación sobre normas preexistente y así se generó violencia. Esto nos autoriza a afirmar que el sistema de derecho en Argentina lleva inscripto en su origen la violencia y ahí reside una de las primeras causas de la desconfianza hacia un ordenamiento que no ha cumplido con la protección que prometía. En otros términos, puede decirse que el derecho como medio de comunicación simbólicamente generalizado $^{14}$ ha sido muy débil.

Tal como señala Neves para el caso de Brasil, en Argentina los golpes militares, que comienzan en 1930 y van hasta 1983, fueron una de las continuas probabilidades y esa misma posibilidad se introdujo en la estructura de expectativas. Devaluaciones de la moneda o incautaciones de los ahorros sin indemnizaciones, como la del año 2001, también son sucesos que marcaron el curso de la comunicación y actuaron como confirmaciones respecto de la inconveniencia del confiar.

En síntesis, si se toma en consideración que una norma se define como una expectativa contrafácticamente estabilizada, puede pensarse ante el panorama recién descrito que dicha comunicación sobre las normas adopta formas diferentes, otros referentes y otros métodos de reestabilización o de sanción. De esto nos ocuparemos en el próximo apartado.

\section{La desutilización o "deflación” del derecho}

Como existe la certeza de que los juicios estarán “arreglados”, de que los policías no serán una solución ante una situación de necesidad o que los jueces son corruptos, los procedimientos fallan por el simple hecho de que no hay disposición para aceptar la decisión que toman esos representantes. Este fenómeno, tal como se argumentó, no es un estado de la opinión pasajero sino una estructura misma y esto significa que las expectativas están teñidas de desconfianza.

Ante las ostensibles dificultades de los procedimientos para que puedan cumplir con su función y dada la imperiosa necesidad de demarcar el futuro con normas, queda pendiente la pregunta por las formas sociales que emergen para cumplir con dicha función. En tal sentido nos introduciremos en las consecuencias de aquello

\footnotetext{
${ }^{14} \mathrm{La}$ definición de este concepto se encuentra en el apartado siguiente.
} 
que damos en llamar desutilización o "deflación del derecho".Vale destacar que éste último - al igual que el dinero, el amor, el poder, la verdad, etc. - es un medio de comunicación simbólicamente generalizado y en cuanto tal funge como garantía para el resguardo de las expectativas comprendidas en la confianza sistémica (Luhmann 2000: 62 ss.). El funcionamiento afirmativo de estos medios, en el sentido de que son capaces de dar continuidad y confirmar las expectativas, permite mantener el nivel de este tipo de confianza.

En términos generales, los medios de comunicación simbólicamente generalizados se encargan de hacer probable, mediante la formación de estructuras de expectativas, la improbabilidad de que Alter acepte la comunicación de Ego (Luhmann 1997: 316). El dinero, por ejemplo, es un medio de comunicación que, en torno a necesidad de reducción de la escasez, está orientado a hacer probable el intercambio de bienes. En tal sentido, alrededor de cada uno de estos medios se forman estructuras de expectativas que hacen que una selección sea relevante para la siguiente. Al respecto, cuando se menciona que los medios generalizados ofrecen la posibilidad de una transferencia intersubjetiva de rendimientos de selección (intersubjektive Übertragbarkeit von Selektionsleistungen) (Luhmann 2000: 61, Luhmann 2005b: 159), se hace referencia a que los medios de comunicación transmiten simbólicamente códigos específicos - tales como la verdad/no verdad, el ser amado/no ser amado, tener poder/no tener poder, justicia/injusticia o el pagar/no pagar - mediante los cuales se puede continuar produciendo selecciones. El producto final de este proceso de estructuración de expectativas - efectuado por los medios de comunicación simbólicos - es que, por ejemplo, exista un intercambio generalizado de bienes (economía), que se pueda aspirar a conseguir "justicia" (derecho), o que se piense posible la acumulación de poder (política).

La pregunta que puede formularse en conexión a nuestra argumentación es la siguiente: ¿qué incidencia tienen para un medio de comunicación simbólicamente generalizado altos niveles de desconfianza? La hipótesis que aquí se propone es que se produce una deflación del derecho o, para expresarlo de otro modo, su desutilización. Con este término se señala la situación en la cual el derecho, como medio de aseguramiento de expectativas, deja de ser atractivo puesto que se reduce la motivación originada en el uso afirmativo de éste tipo de comunicación (Luhmann 1997:382 s). Se trata de un proceso mediante el cual se comprueba que la confianza en el derecho no puede actualizarse porque las expectativas prometidas no se confirman.

Además, considerando ciertos eventos significativos que se encuentran en la memoria del sistema y que sin duda afectan la orientación que toma la comunicación dentro del mismo, puede insistirse en la tesis según la cual existe una escasa probabilidad de que el medio derecho pueda ser objeto de confianza y por lo tanto utilizado. Este fenómeno sin duda también se encuentra influido por la fragilidad del derecho origi- 
nada en el hecho de que, a diferencia de otros medios de comunicación, la confianza en él puede ser perdida muy rápidamente, al tiempo que es dificil de recuperarla.

Pueden ilustrar esta desutilización del derecho al menos dos ejemplos relacionados a la Argentina: en primer lugar, procesos de hiperinflación de una gravedad inusitada, donde el derecho a causa de una irritación excesiva no puede asegurar las expectativas comprendidas en contratos que se ven desactualizados constantemente. En segundo lugar, como lo hemos descrito al principio de este trabajo, una situación donde sólo un 25 \% de los afectados por delitos hacen uso del sistema de derecho.

Entonces, en el marco de esta manifiesta desconfianza hacia un derecho que en efecto demuestra no servir como resguardo, es la legitimación del mismo sistema político y de derecho la que se ve perjudicada, ello en tanto se apoye la idea de que ella se logra gracias al funcionamiento de procedimientos específicos. Si esto es así, lo dicho en el capítulo sobre los procedimientos fallidos y lo expuesto precedentemente acaso nos presente ahora un mejor panorama de la conexión entre ambas dimensiones: las posibilidades de los procedimientos para producir una disposición orientada a la aceptación de decisiones vinculantes encuentran su límite en una desconfianza que, lejos de ser un "estado de ánimo" de la población cristalizado en encuestas, es una densa estructura de expectativas cuyo principio se remonta a hechos traumáticos que obstruyeron al derecho.

Sin embargo, en el marco de la investigación que se vale de la teoría de sistemas de Luhmann y que se enriquece teóricamente buscando equivalentes funcionales, el hecho significativo no sólo reside en que el derecho como medio de comunicación simbólico deflaciona, sino en que éste compite con otros medios que también cumplen con la función de asegurar normativamente las expectativas. Aquí se indica que, en forma paralela a la desutilización del derecho, emergen otras estructuras de expectativas que tienen la capacidad para absorber inseguridad y señalizar el futuro con normas. Se trata de un proceso que comprende la desconfianza en el derecho como medio de estabilización de las expectativas y un correlativo surgimiento de confianza en el marco de contextos normativos con características propias.

Como se ha sostenido en otro lugar (Dewey 2007), estas estructuras adoptan configuraciones singulares y suelen ser denominadas relaciones clientelares, mafiosas, redes de favores, etc. Sus particularidades se desprenden del tipo de confianza que actúa como medio: las expectativas ya no anclan en una confianza abstracta y sistémica como el derecho, sino en una confianza de tipo personal que confiere al nivel de la interacción una gravitación especial cuando se trata de observar el fenómeno de generación de normas. Uno de los caracteres más visibles de estas estructuras son sus horizontes temporales de corto plazo dado que las normas que entran en vigencia se fijan situacionalmente; es decir, predomina la situación por sobre la generalización (Luhmann 2005e: 241 ss.). 
Esto no significa, sin embargo, que necesariamente aquello que ha de esperarse normativamente se estipula por completo en cada situación; como muestran ciertos estudios ${ }^{15}$, aquello que se conviene normativamente en situaciones de interacción puede permanecer en el tiempo. Éstas constituyen tanto un espacio de emergencia de aquello que habrá de esperarse normativamente como de verificación constante de la validez de dichas normas.Vale la pena reiterar que esto es posible, pues ante la falta de estabilización por parte del sistema de derecho, se crean otros mecanismos que adoptan esa función. Como afirma Luhmann en relación al sur de Italia (Luhmann 1995), el metacódigo "inclusión/exclusión" se transforma en una diferencia directriz cuya relevancia es superior a cualquier otro código: la violación de las normas recién descritas se pagan con la exclusión y esto significa tanto perder la posibilidad de ser reconocido como persona ${ }^{16}$, como aumentar en exceso los niveles de inseguridad de expectativas. La exclusión es el lugar del no-suceso (Stichweh 2000: 86).

De lo descrito en este último apartado puede desprenderse que el déficit en la aplicabilidad del derecho conduce a que éste último deje de ser una garantía de las expectativas en caso de frustración y a que se formen estructuras que pretenden asumir esta tarea.

\section{Conclusión}

Se dio comienzo al presente artículo mostrando que la investigación en Argentina, en torno al problema de las leyes y la realidad de las mismas, había observado este fenómeno en términos de anomia, en especial según la concepción de Durkheim. Conforme a esto, se vio que tanto Germani como Waldmann consideran al Estado como fuente de normatividad en la sociedad moderna y que, de acuerdo a ello, ambos se ven en la inevitable necesidad de introducir la perspectiva de Weber acerca de la dominación racional. El resultado de este racionamiento fue sin dudas un entendimiento de la anomia estrechamente ligado al Estado y que alude a la transgresión o incumplimiento de las normas que componen a éste. Por otro lado, enfoques de esta problemática, como los de Nino u O'Donnell, que no se valen del término de anomia pero que se inclinan en cambio hacia una observación que emplea la diferencia "legal/ilegal", no han llegado mucho más lejos puesto que siguen describiendo y constatando, al igual que Waldmann, lo consabido; esto es, que existe una amplia

\footnotetext{
${ }^{15}$ Una institucionalización de procedimientos estructurados normativamente, pero a la sombra del sistema de derecho, son particularmente visibles en el caso de la mafia. El alto grado de estabilidad de algunos grupos mafiosos, tales como los estudiados por Gambetta (2007), se advierte en su capacidad para disputarle al Estado el monopolio de la fuerza. ${ }^{16}$ Cabe indicar que el concepto de persona, en el sentido de la teoría de sistemas, se entiende como una construcción de la comunicación y para la comunicación. Estas construcciones constituyen elementos relevantes en los procesos comunicativos que tienen lugar dentro los sistemas parciales u organizados (organizaciones). La participación en estos procesos significa el reconocimiento de las personas como instancias distinguidas por su importancia social. Las personas son estructuras de la comunicación (Luhmann, 2005d, Fuchs 2004: 131).
} 
brecha entre la poca legitimidad de las normas pertenecientes al sistema de derecho y la alta legitimidad de entramados normativos paralelos.

En orden a realizar un aporte teórico a la cuestión planteada, se propuso un abordaje desde la teoría de sistemas de Niklas Luhmann en vistas de su capacidad para responder a la pregunta de porqué un orden racional legal en cierto modo se rechaza y porqué otro/s orden/es se aceptan como válidos. En tal sentido la teoría de la legitimación por procedimientos constituye un aporte sustantivo. Ella viene a señalar cuál es la función de los procedimientos y cuáles son los componentes estructurales que facilitan una disposición para la aceptación de decisiones vinculantes.

Sin embargo, nuestra propuesta, tomando en consideración datos empíricos que muestran una ostensible impugnación de las normas del sistema de derecho, invirtió la pregunta y se interroga por aquellos mecanismos que impiden a los procedimientos el cumplimiento de su función o, en otros términos, que ocasionan que las normas no sean aceptadas. Las ventajas que comporta el empleo de la noción de procedimiento fallido reside en suponer la consabida diferencia entre el texto y su realidad e ir más allá proponiendo un esquema teórico que arroja luz tanto sobre los mecanismos que impiden la aceptación de normas como sobre los orígenes y las derivaciones del fenómeno.

Los procedimientos fallan porque existe una desconfianza que circula en la comunicación que pone en duda de modo continuo la posibilidad de que las expectativas positivas (confianza) depositadas en roles específicos - juez, policía, político, etc. sean reestabilizadas en caso de lesión. Esta desconfianza presente en la comunicación tiene como correlato la eliminación de la incertidumbre acerca del desenlace que requiere todo procedimiento para poder cumplir con su función. La ausencia de este componente, que al estar presente motiva a los participantes a continuar participando en los procedimientos, es el resultado de la desconfianza y de la certeza de que el confiar, tarde o temprano, conducirá a la frustración de las expectativas invertidas.

En el capítulo tres se aportaron datos empíricos que permiten constatar que las normas y procedimientos dispuestos por el sistema de derecho no se encuentran dentro del horizonte de expectativas del $75 \%$ de la población que fue víctima de delitos. Adicionalmente, las cifras expuestas señalan una fuerte desconfianza en aquellos roles que al término de los procedimientos adoptan las decisiones con pretensión vinculante. En el capítulo cuatro se aludió a la profundidad de esta desconfianza puesto que no se trata de un "estado de ánimo" de la población reflejado en las encuestas, sino de un fenómeno arraigado en la comunicación y que puede ser parte de una semántica que emerge a partir de una historia de sucesos de de frustración sin reacción por parte del sistema de derecho. Entre estos sucesos, entre otros, cuentan los golpes de estado, las confiscaciones de ahorros y los procesos hiperinflacionarios. 
En el último capítulo se han tratado las consecuencias de este proceso de constantes sucesos de "frustración/no estabilización de las expectativas" que condujeron finalmente hacia una desconfianza institucionalizada. La desutilización del derecho o la deflación del mismo como medio para el aseguramiento de las expectativas normativas es una clara consecuencia. El derecho, como medio que dispone una señalización del futuro a través de normas, pierde su atractivo porque existe la cuasi certeza de que fallará en el cumplimiento de su función. En este contexto de desconfianza, las decisiones que se adoptan en los procedimientos no son aceptadas porque no existe la disposición al riesgo que sólo la confianza, a partir de una historia de resultados afirmativos, puede facilitar.

Desde el punto de vista teórico, hacia el final del presente trabajo pueden destacarse dos aspectos que resultan novedosos para el análisis de la problemática de las normas del sistema de derecho en el contexto argentino.

En primer lugar, se trata de un cambio de perspectiva que se ofrece gracias a la teoría de sistemas de Luhmann. Definir al derecho a través de su función y considerar que ésta consiste en la estabilización contrafáctica de expectativas normativas, permite interrogarse no sólo por las consecuencias de un sistema que no cumple con su tarea, sino que además, y gracias a la lógica del método de las equivalencias funcionales, es posible analizar las posibles estructuras que asumen la función del derecho. Adicionalmente, el empleo de la teoría de la legitimación por procedimientos apunta a un problema que hasta ahora tanto Waldmann como Nino y O’Donnell habían dejado sin respuesta: el proceso de "cómo cambian las expectativas" o cómo se forma la "creencia" en un orden legal. El procedimiento es aquella instancia orientada a una transformación de las expectativas sociales y, en tal sentido, que puede producir la legitimación de decisiones vinculantes. El reconocimiento de la misma es fundamental en tanto deja de centrarse el problema en los individuos y su inmoralidad, y propone considerar la aceptación - o no - de normas a partir del funcionamiento y capacidad estructural de los procedimientos para transformar estados de lo esperable.

En segundo lugar, se destacan las ventajas provenientes del concepto de "memoria del sistema" y del método de las equivalencias funcionales. La constante y renovada tematización en el presente de sucesos de transgresión normativa ocurridos en el pasado, nos revela que la comunicación sobre normas del hoy se encuentra condicionada por eventos significativos pretéritos. Esta observación nos lleva a inferir que la ausencia de incertidumbre, que significa una falla estructural del procedimiento, encuentra su origen en un sistema de derecho que no ha podido garantizar una reacción adecuada ante la lesión de las expectativas y que, consecuentemente, ha engendrado la certeza de que no es posible confiar. La fortaleza de esta desconfianza descansa en el pasado y es la que sustrae la incertidumbre que necesitan los procedimientos introduciendo una certeza negativa. 
Por otra parte, el método de las equivalencias funcionales permite detectar estructuras que pueden entenderse como la consecuencia de este proceso. Los entramados de expectativas de las relaciones patrón-cliente, de las redes de favores o del clientelismo - entre otros - son formas institucionalizadas y reforzadas que surgen ante la necesidad de abrir espacios futuros y de asegurar las expectativas que ellos contienen. De modo diverso estas estructuras también señalizan el futuro estipulando qué habrá de poder esperarse y prometiendo una estabilización cuando sobrevenga la frustración. Entonces, la teoría de los procedimientos fallidos, beneficiada por el instrumental conceptual de la teoría de sistemas, constituye una explicación plausible a la cuestión de la brecha entre el texto constitucional y su realidad. Se trata, en última instancia, de una respuesta al problema de la legitimidad de la legalidad y a su opuesto, el de la legitimidad de la ilegalidad. 


\section{Bibliografía}

Auyero, J. (2007): La zona gris: violencia colectiva y política partidaria en la Argentina contemporánea. Siglo Veintiuno Editores, Buenos Aires.

Auyero, J. (2001): La política de los pobres. Las prácticas clientelísticas del peronismo. Ediciones Manantial, Buenos Aires.

Burden, B. (2003): Uncertainty in American Politics, Cambridge University Press, New York.

Dewey, M. (2007): "Frustración, desconfianza y emergencia de la informalidad", en: Lateinamerika Analysen, 18, 3, pp. 1-29.

Durkheim, É. (1925): L'éducation morale. Alcan, Paris.

Elias, N. (1988): Über die Zeit, Suhrkamp, Frankfurt am Main.

Elster, Jon (2007): Rendición de cuentas, Ed. Katz, Buenos Aires.

Encuestas de victimización en Argentina, <http://www.polcrim.jus.gov.ar/>, (Enero 2008) - (10.01.2008).

Fuchs, P. (2004): Der Sinn der Beobachtung. Velbrück Wissenschaft, Weilerwist.

Gambetta, D. (2007): La mafia siciliana. FCE, México.

Germani, G (1945). Anomia y desintegración social. Boletín del Instituto de sociología, IV, Buenos Aires.

Germani, G. (1971): Política y sociedad en una época de transición, Paidós, Buenos Aires.

Girolda, L. (2005): Anomia e individualismo. Del diagnóstico de la modernidad de Durkheim al pensamiento contemporáneo. Anthorpos, Barcelona.

Habermas, J. (1973): Legitimationsprobleme im Spätkapitalismus. Suhrkamp, Frankfurt am Main.

Habermas, J. (1976): Zur Rekonstruktion des historischen Materialismus, Suhrkamp, Frankfurt am Main.

Heidorn, J. (1982): Legitimität und Regierbarkeit. Studien zu den Legitimitätstheorien von Max Weber, Niklas Luhmann, Jürgen Habermas und der Unregierbarkeitsforschung. Dunkker \& Humblot, Berlin.

Índice de Confianza en la Justicia, <www.utdt.edu/ver_contenido.php?id_ contenido=1452\&id_item_menu=1592>, $($ Enero 2008) $-(10.01 .2008)$ 
Latinobarómetro, <www.latinobarometro.org/>, (Enero 2008) - (10.01.2008)

Luhmann, N. (1980): Gesellschaftliche Struktur und semantische Tradition, en: ibid, Gesellschaftsstruktur und Semantik. Suhrkamp, pág. 9-71.

Luhmann, N. (1983): Legitimation durch Verfahren. Suhrkamp, Frankfurt am Main.

Luhmann, N. (1984): Soziale Systeme. Grundriß einer allgemeinen Theorie. Suhrkamp, Frankfurt am Main.

Luhmann, N. (1987): Rechtssoziologie. WestdeutscherVerlag, Opladen.

Luhmann, N. (1995): Kausalität im Süden. En: Soziale Systeme, No 1/1, pp. 7-28.

Luhmann, N. (1997): Die Gesellschaft der Gesellschaft. Suhrkamp, Frankfurt am Main, Tomo I.

Luhmann, N. (2000): Vertrauen, Lucius \& Lucius, Stuttgart.

Luhmann, N. (2005a): "Soziologie des politischen Systems". En: ibid, Soziologische Aufklärung 1,VS Verlag, pág. 194-223.

Luhmann, N. (2005b): "Soziologie als Theorie sozialer Systeme”. En: ibid, Soziologische Aufklärung 1,VS Verlag, Wiesbaden, pág. 143-172.

Luhmann, N. (2005c): "Die gesellschaftliche Differenzierung und das Individuum", en: ibid, Soziologische Aufklärung 6,VS Verlag, Wiesbaden, pág. 121-136.

Luhmann, N. (2005d): "Die Form 'Person'”. En: ibid, Soziologische Aufklärung 6,VS Verlag, Wiesbaden, 2005d, pág. 137-148.

Luhmann, N. (2005e): "Inklusion und Exklusion”. En: ibid, Soziologische Aufklärung 6,VSVerlag, Wiesbaden, pág. 226-251.

Lukes, S. (1973): Émile Durkheim. His life and work. Penguin Books, Harmondsworth.

Mascareño, A. (2001): Funktionale Differenzierung und Steuerungsprobleme in Lateinamerika: Entstehung, Entwicklung und Aufösung der konzentrisch orientierten Ordnung. Bielefeld, Tesis Doctoral.

Mascareño,A. (2004): “Sociología del derecho (chileno y latinoamericano)". En: Revista Persona y Sociedad, Vol. XVIII, N 2, Agosto.

Morales Saravia, J. (2001): "Semántica de la desilusión en 'El juguete rabioso' de Roberto Arlt". En: Ibid,Arlt, Roberto: Una modernidad argentina, Vervuert, Frankfurt, pág. 27-45. 
Neves, M. (1992): Verfassung und Positivität des Rechts in der peripheren Moderne. Duncker \& Humboldt, Berlin.

Nino, C. S. (1992): Un país al margen de la ley: estudio de la anomia como componente del subdesarrollo argentino. Emecé, Buenos Aires.

O’Donnell, G. /Méndez, J. E. (2002): La (in)efectividad de la ley y la exclusión en América Latina. Paidós, Buenos Aires.

O’Donnell, G. (2007): Disonancias. Críticas democráticas a la democracia. Prometeo, Buenos Aires.

Przeworski,A. (1988): "Democracy as a contingent outcome of conflicts". En: Elster, Jon y Slagstad, Rune, Constitutionalism and Democracy, Cambridge University Press, New York.

Saguier, E. R. (1992): “La corrupción en la burocracia colonial borbónica y los orígenes del federalismo. El caso del Virreinato del Río de la Plata”. En: Kahle, Günter (Et. al.), Jahrbuch für Geschichte von Staat, Wirtschaft und Gesellschaft Lateinamerikas, Böhlau Verlag, Colonia, pág. 149-177

Smithson, M. (1989): Ignorance und Uncertanity. Emerging Paradigms, Springer, New York.

Stichweh, R. (2000): Die Weltgesellschaft, Suhrkamp, Frankfurt am Main.

Van Kesteren, J. (Et. al.) (2008): Criminal victimisation in seventeen industrialised countries. <www.wodc.nl/Onderzoeken/Onderzoek_W00187.asp>, (Enero) - (10.01.2008)

Waldmann, P. (2006): El Estado anómico, Iberoamericana/Vervuert, Madrid.

Weber, M. (1997): Wirtschaft und Gesellschaft, Mohr Siebeck, Stuttgart. 